\begin{tabular}{l|l|l|l|l|l} 
Revista Duazary & ISSN: 1794-5992 & Vol. 12 & No. 2 & $174-181$ & Julio - Diciembre de 2015 \\
\hline
\end{tabular}

\title{
INFECCIÓN POR VIRUS DEL ÉBOLA. CORTA HISTORIA, LARGA REPERCUSIÓN
}

\author{
EBOLA VIRUS DISEASE. SHORT HISTORY, LONG IMPACT
}

\author{
TITULO CORTO: INFECCIÓN POR VIRUS ÉBOLA
}

\begin{abstract}
$M^{\mathrm{a}}$ Teófila Vicente-Herrero' ${ }^{1}$, Ángel Arturo López-González ${ }^{2}, \mathbf{M}^{\mathrm{a}}$ Victoria Ramírez-Iñiguez de la Torre $^{3}$, Luisa M. Capdevila-García ${ }^{4}, M^{a}$ Jesús Terradillos-García $^{5}$ y Encarna Aguilar-Jiménez ${ }^{6}$
\end{abstract}

Recibido en febrero 09 de 2015

Aceptado en mayo 19 de 2015

\section{RESUMEN}

La Infección por virus ébola constituye en el momento actual una preocupación creciente en el mundo, aunque su historia se remonta a 1967, con brotes posteriores en 1979, 1980 y 1987, todos ellos en trabajadores por contacto en zonas afectadas. La preocupación de la comunidad científica por este tema, puede verse parcialmente reflejada en las publicaciones que recoge MEDLINE, en la base de datos PUBMED y en las que tomando como palabra clave en el buscador (Ebola virus) aparecen 2.151 publicaciones, 984 de las cuales corresponden a los últimos 5 años $(45,7 \%)$ y 527 de estas publicaciones (el 53,5\%) a los años 2014-2015. La primera publicación que consta es de 1977, sin autor listado ni abstract de referencia, y la más reciente de enero del presente año 2015. Todo ello habla de un problema globalizado y que preocupa a la comunidad científica internacional. Se realiza en este trabajo una revisión de algunos de los estudios publicados en esta materia, considerados de interés y comentados por los autores.

Palabras Clave: Ebolavirus; Salud Pública; Bibliografía como asunto (fuente DeCs)

\section{Abstract}

Ebola Virus infection is at present times a growing worldwide concern, although its history goes back to 1967, with subsequent outbreaks in 1979, 1980 and 1987, all of them by contact in workers in affected areas. The concern of the scientific community about this issue is partially reflected in publications included in MEDLINE (PUBMED

1. Doctora en Medicina. Especialista en Medicina del Trabajo. Servicio de Prevención de Riesgos Laborales. Grupo Correos-Valencia-España. Correo electrónico: mtvh@ono.com

2. Doctor en Medicina. Especialista en Medicina del Trabajo. Servicio de Prevención de Riesgos Laborales IBSALUT. Islas Baleares-España. Correo electrónico: angarturo@gmail.com

3. Licenciada en Medicina. Especialista en Medicina del Trabajo. Servicio de Prevención de Riesgos Laborales. Grupo Correos, Albacete-España. Correo electrónico: virirrami@gmail.com

4. Doctora en Medicina. Especialista en Medicina del Trabajo. Servicio de Prevención Mancomunado, MAPFRE, Valencia-España. Correo electrónico: lcapdevila@mapfre.com

5. Licenciada en Medicina. Especialista en Medicina del Trabajo. Instituto Nacional de la Seguridad Social, Madrid - España. Correo electrónico: mjtginss@hotmail.com

6. Licenciada en Medicina. Especialista en Medicina del Trabajo. Instituto Nacional de la Seguridad Social, Valencia-España. Correo electrónico: aguilar. encarna@gmail.com 
database) and in which, taking as a keyword in the search box "Ebola virus", 2.151 publications are found, belonging 984 of them to the last 5 years $(45.7 \%)$ and 527 of these publications (53.5\%) to the years 2014-2015. The earliest publication dates back to 1977, attaching no listed authors either reference abstract, and the most recent to January of current year 2015. This means Ebola infection is a global problem and that concern the international scientific community. A review of some of the studies published in this matter, considered of interest and discussed by the authors, is performed in this work.

Keywords: Ebolavirus; Public Healh; Bibliography (fuente MeSH)

\section{INTRODUCCIÓN}

La infección por virus ébola constituye en el momento actual una preocupación creciente en el mundo. El brote de 2014 es considerado el mayor de la historia y causa de la fiebre hemorrágica en los primates humanos y no humanos con alta tasa de mortalidad que llega hasta el $90 \%$, y se puede transmitir por contacto directo con sangre, fluidos corporales o la piel de los pacientes con Enfermedad por Virus Ébola (EVD) o personas que han muerto de EVD, siendo el personal más sensible al contagio el de los trabajadores sanitarios. Se conocen hasta diciembre de 2014, 450 trabajadores sanitarios infectados por ébola, de los cuales 244 murieron. A esto se une la dificultad para el desarrollo de la vacuna y del tratamiento del ébola, puesto que se encuentra en un nivel 4 de bioseguridad en cuanto a su accesibilidad (BSL-4) que lo hace especialmente peligroso para llevar a cabo experimentos. En el momento actual no hay vacuna, ni tratamiento específico; sin embargo, se están desarrollando muchas vacunas y antivirales como ZMapp y TKM- Ébola ${ }^{1}$.

Para poder clarificar lo que comporta, parece necesario definir, en primer lugar, el concepto de enfermedad emergente y reemergente en el cual se enmarca.

Son enfermedades infecciosas emergentes aquellas recién descubiertas y causantes de severos problemas de salud, tanto local como internacionalmente. En los últimos 20 años se han descubierto más de 30 nuevos gérmenes productores de nuevas enfermedades o síndromes. Dentro de este grupo de enfermedades se incluyen la fiebre hemorrágica producida por el virus ébola, que por su capacidad de diseminación ha causado pánico en algunos países africanos.
Como enfermedades reemergentes se consideran aquellas supuestamente controladas, en franco descenso o prácticamente desaparecidas, que vuelven a constituir una amenaza sanitaria y que frecuentemente reaparecen en proporciones epidémicas, ejemplo de ellas estaría la tuberculosis, debido en parte a la asociación con la infección con el VIH a nivel mundial; lo mismo ocurre con enfermedades que eran prevenibles por medio de vacunas como la difteria y la poliomielitis y vuelven actualmente a ser una prioridad epidemiológica en países desarrollados que llevaban años sin ellas y por diversas razones, algunas de indole económico o social².

Lo que resulta evidente es que se trata de una enfermedad infecciosa global, catalogada como una nueva infección emergente, de la que se tiene un conocimiento todavía limitado y en la que los asuntos pendiente de discusión parten de su forma atípica de presentación, de la necesidad de nuevas herramientas diagnósticas, tratamientos específicos eficaces y se destaca la importancia de realizar un esfuerzo en la mejora e implantación de procedimientos preventivos ${ }^{3}$.

\section{Un recuerdo histórico}

El virus Ébola (VE) ha formado parte de la actualidad en los últimos años por el brote de alta letalidad aparecido en el continente africano, si bien la historia se remonta a 1967 en el que los escritos refieren a este virus junto con el virus Marburg, llegando a Europa desde Uganda y por medio de la transmisión de monos de la especie Cercopithecus aethiops que habían de ser utilizados en los laboratorios de Alemania y de la antigua Yugoslavia.

El contagio a través de los desechos de los animales afectó al personal encargado de su manejo provocando 
un cuadro de gran virulencia y altas tasas de mortalidad ( $23 \%$ de letalidad) que se iniciaba con una sintomatología inespecífica: fiebre, cefalea, mialgias y malestar, seguido de inyección conjuntival, fotofobia y un exantema generalizado, a la que seguían otros síntomas más severos como: bradicardia, diarrea, oliguria e ictericia leve. Las pruebas de laboratorio aportaron información poco precisa: elevación de las transaminasas, leucopenia con linfocitosis y trombocitopenia.

El Microbiological Research Establishment, a través del equipo encabezado por C.B. Gordon Smith, llevó a cabo el aislamiento del agente etiológico, aunque no fue hasta tres años más tarde cuando se pudo establecer la identidad virológica de este agente y ubicarlo en la familia Filoviridae. En ese momento se lo denominó virus de Marburg, por haber sido esta la ciudad más afectada.

Este virus no volvió a reaparecer hasta ocho años más tarde. En 1975 un viajero que recorría Rodesia, hubo de ser internado en un hospital de Sudáfrica, donde falleció. Un año después, casos similares se presentaron casi simultáneamente en dos regiones del continente africano. 318 personas en la zona de Bumba, en el norte de Zaire (letalidad del 90\%) y 250 casos en la zona sur de Sudán (Nzara, Maridi y Lirangu) (letalidad del 60\%-80\%).

La mayor diseminación del virus se produjo en forma intrahospitalaria, por contacto persona a persona y por la reutilización de agujas contaminadas.

Puestos en coordinación los laboratorios de alta seguridad en Estados Unidos, Bélgica e Inglaterra coincidieron en que el virus era morfológicamente igual al Marburg, un Filoviridae, pero serológicamente distinto. Por ello, se concluyó estar ante un nuevo virus y el Dr. E.T. Bowen y el profesor S.R. Pattyn, del Institute of Tropical Medicine de Antwerp utilizaron para su denominación el nombre de un pequeño río de Zaire, al norte de Yambuku. De este poblado provenía el paciente del cual se hizo el primer aislamiento del virus, Ébola.

Tras el brote original de 1976, se sucedieron otros en 1979, 1980 y 1987, todos ellos en trabajadores por contacto en zonas afectadas ${ }^{4}$.

\section{El virus ébola en el momento actual}

La preocupación de la comunidad científica por este tema puede verse parcialmente reflejada en las publicaciones que recoge la base de datos médica de mayor referencia
(PUBMED), y en las que tomando las palabras clave más frecuentemente utilizadas por los investigadores, se observa que el mayor porcentaje se corresponde con los últimos 5 años. La primera publicación que consta en esta base de datos es de 1977, sin abstract de referencia ${ }^{5}$, y la más reciente de enero del presente año $2015^{6}$ (Tabla 1) (figuras 1 y 2). Todo ello habla de un problema globalizado y que preocupa a la comunidad científica internacional.

Se comentan a continuación algunas de las publicaciones más recientes destacadas, a criterio de los autores, por su interés:

Uno de los aspectos que más preocupa, dada la complejidad de la enfermedad en curso, es la necesidad que se plantea de revisar las características epidemiológicas de la enfermedad, la dinámica de su transmisión y el efecto obtenido con las intervenciones de lucha contra la transmisión del virus ${ }^{7}$. Se trata de utilizar modelos matemáticos que permitan establecer patrones de comparación en la propagación y control, en el contexto de brotes anteriores y del actual del África occidental. Estos modelos pueden ser de apoyo al ofrecer información útil sobre el riesgo de una importante epidemia y la evaluación del impacto de las medidas básicas de salud pública en la propagación de la enfermedad. Algunos autores recalcan en sus trabajos la necesidad de recoger datos epidemiológicos detallados en tiempo real, durante el curso de una epidemia, llevar a cabo más estudios para estimar la eficacia de las intervenciones durante los brotes del pasado y de la epidemia en curso, y desarrollar estudios de modelos a gran escala para estudiar la propagación y control de las fiebres hemorrágicas virales, en el contexto de una realidad económica muy heterogénea como lo es la de los países africanos ${ }^{8}$.

Si bien la infección por VE afecta en el momento actual a múltiples países, no cabe duda de que la mayor y más creciente preocupación se focaliza en el África subsahariana, por la carga que supone en salud pública. Desde 1976, se han registrado 885.343 casos sospecha y se han confirmado en laboratorio otros 2.512 con una letalidad elevada, 932 de ellos en el África occidental.

Hay ciertos requisitos que se deben cumplir al responder a los brotes de VE y este proceso podría incurrir en ciertos desafíos. Cinco han sido identificados:

1. Deficiencia en el desarrollo e implementación de sistemas de respuesta de vigilancia contra el ébola y otros brotes de enfermedades infecciosas en África. 
2. Falta de educación y conocimiento en el manejo de la situación que ocasionará como resulta del brote síntomas de pánico, ansiedad, trauma psicosocial, aislamiento y afectación de la dignidad, genera estigmatización, ostracismo y resistencia a las consecuencias de salud socio-ecológicas.

3. Recursos financieros limitados, capacidad humana y técnica de una comunidad débil y en un sistema de salud con limitaciones en planes operativos, respuestas de prevención, control y gestión.

4. Liderazgo y coordinación inadecuada

5. Falta de desarrollo de nuevas estrategias, herramientas y enfoques, como la mejora de los diagnósticos y terapias novedosas que incluyen vacunas que pueden ayudar en la prevención, control y contención de brotes de ébola, así como la propagación de la enfermedad.

Tabla 1. Publicaciones MEDLINE Virus Ébola. Comparativo últimos 5-10 años

\begin{tabular}{|c|c|c|c|}
\hline \multirow[b]{2}{*}{ Término de búsqueda } & \multicolumn{2}{|c|}{ Últimos 5 años } & \multirow[b]{2}{*}{$\begin{array}{c}\text { Últimos } 10 \text { años } \\
\text { (número de publicaciones) }\end{array}$} \\
\hline & $\begin{array}{c}\text { número de } \\
\text { publicaciones }\end{array}$ & $\begin{array}{c}\% \text { respecto } \\
\text { al total de los } \\
\text { últimos } 10 \text { años }\end{array}$ & \\
\hline ebola & 1706 & $79,50 \%$ & 2146 \\
\hline ebola review & 164 & $66,13 \%$ & 248 \\
\hline ebola vaccine & 291 & $73,49 \%$ & 396 \\
\hline ebola vaccine review & 56 & $67,47 \%$ & 83 \\
\hline ebola virus & 1051 & $72,68 \%$ & 1446 \\
\hline ebola virus review & 134 & $64,42 \%$ & 208 \\
\hline ebola virus disease & 989 & $78,93 \%$ & 1253 \\
\hline ebola virus disease review & 122 & $66,67 \%$ & 183 \\
\hline ebola transmission & 248 & $74,70 \%$ & 332 \\
\hline ebola transmission review & 47 & $61,04 \%$ & 77 \\
\hline ebola transmission risk & 62 & $80,52 \%$ & 77 \\
\hline ebola treatment & 636 & $78,52 \%$ & 810 \\
\hline ebola and treatment and review & 85 & $64,89 \%$ & 131 \\
\hline ebola hemorrhagic & 781 & $76,64 \%$ & 1019 \\
\hline ebola hemorrhagic review & 98 & $64,05 \%$ & 153 \\
\hline ebola outbreak & 530 & $82,81 \%$ & 640 \\
\hline ebola outbreak review & 72 & $72 \%$ & 100 \\
\hline ebola virus pathogenesis & 488 & $60,77 \%$ & 803 \\
\hline ebola virus pathogenesis review & 77 & $55,80 \%$ & 138 \\
\hline ebola infection & 947 & $76,80 \%$ & 1233 \\
\hline ebola infection review & 124 & $68,13 \%$ & 182 \\
\hline ebola hemorrhagic fever & 746 & $76,83 \%$ & 971 \\
\hline ebola hemorrhagic fever review & 87 & $63,50 \%$ & 137 \\
\hline ebola virus infection & 908 & $76,24 \%$ & 1191 \\
\hline ebola virus infection review & 117 & $66,86 \%$ & 175 \\
\hline ebola pathogenesis & 571 & $62,68 \%$ & 911 \\
\hline
\end{tabular}




\begin{tabular}{|c|c|c|c|}
\hline \multirow[b]{2}{*}{ Término de búsqueda } & \multicolumn{2}{|c|}{ Últimos 5 años } & \multirow[b]{2}{*}{$\begin{array}{c}\text { Últimos } 10 \text { años } \\
\text { (número de publicaciones) }\end{array}$} \\
\hline & $\begin{array}{c}\text { número de } \\
\text { publicaciones }\end{array}$ & $\begin{array}{c}\% \text { respecto } \\
\text { al total de los } \\
\text { últimos } 10 \text { años }\end{array}$ & \\
\hline ebola pathogenesis review & 85 & $55,56 \%$ & 153 \\
\hline ebola virus treatment & 411 & $72,61 \%$ & 566 \\
\hline ebola virus treatment review & 34 & $75,56 \%$ & 45 \\
\hline $\begin{array}{l}\text { correlates of protective immunity for ebola } \\
\text { vaccines }\end{array}$ & 1 & $50 \%$ & 2 \\
\hline
\end{tabular}

Fuente. PubMED-http://www.ncbi.nlm.nih.gov/pubmed/25694090. Búsqueda realizada 20/02/2015

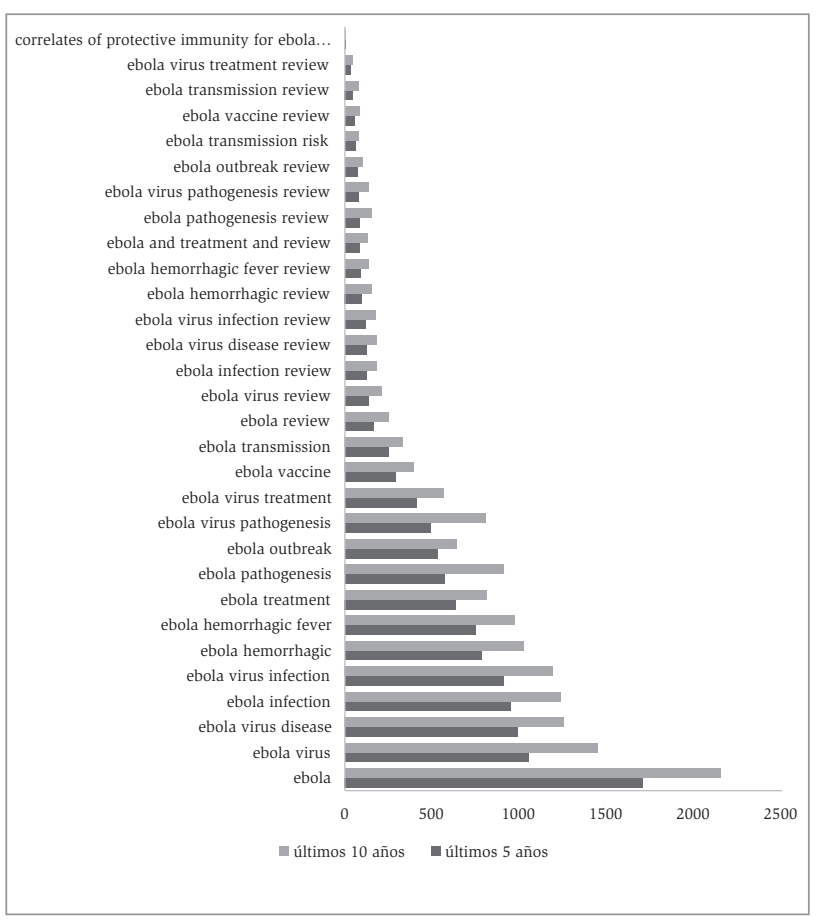

Figura 1.- Número de artículos sobre ebola publicados en los últimos 5 y 10 años según descriptor.

Fuente. PubMED-http://www.ncbi.nlm.nih.gov/ pubmed/25694090. Búsqueda realizada 20/02/2015

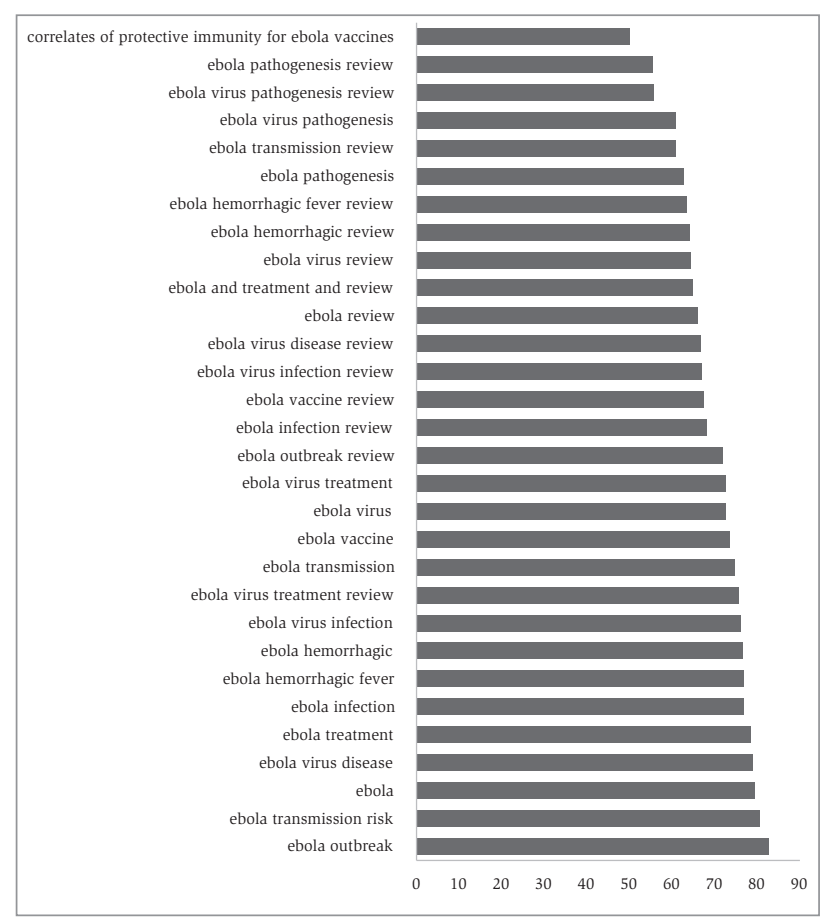

Figura 2. Número de artículos sobre Ébola publicados en los últimos 5 años sobre Ébola respecto del total de los publicados en los últimos 10 años según descriptor.

Fuente.PubMED-http://www.ncbi.nlm.nih.gov/ pubmed/25694090.Búsqueda realizada 20/02/2015
Por lo tanto, existe una necesidad urgente de desarrollar y poner en práctica una alerta y respuesta temprana para la vigilancia activa de respuesta a brotes y control de las enfermedades infecciosas emergentes.

En Sierra Leona, desde mayo de 2014 a enero de 2015, el centro de Operaciones de Emergencia puso en marcha un centro de llamadas para fomentar la denuncia pública de posibles casos de ébola y de muertes, a los funcionarios de salud pública, que de esta forma proporcionan también educación para la salud sobre el ébola a las personas que llaman. Esta información funciona de este modo como un sistema de "alerta" para los funcionarios de salud pública y apoya los esfuerzos de vigilancia de 
la respuesta9 . Es necesario conocer en profundidad los riesgos de transmisión de la enfermedad para implementar intervenciones rápidas y respuestas eficaces adaptadas a entornos y contextos locales específicos.

Se requiere por ello una rápida actuación por los ministerios y organizaciones aliadas de los países africanos en respuesta a la pandemia, un compromiso de defensa de una financiación sostenida, la creación de redes que incluyan participación de la comunidad para mejorar una respuesta coordinada, así como el seguimiento de gestión. Junto con ello, promover más investigación y desarrollo en el descubrimiento de nuevos medicamentos y vacunas; participación de la salud mundial para promover el establecimiento de sistemas de respuesta de vigilancia de salud pública con funciones de alerta temprana; y programas de investigación-acción e intervenciones innovadoras ${ }^{10}$.

Algunos autores apoyan el uso de modelos de transmisión calibrados cuidadosamente, con potencial para orientar a los responsables en salud pública de la naturaleza y la escala de las intervenciones necesarias para controlar las epidemias. En el contexto de la epidemia de la enfermedad del virus ébola en curso, Drake et al. ${ }^{11}$, han empleado un enfoque basado en un modelo para capturar las distribuciones del número de casos secundarios que surgen en la atención comunitaria, con ajustes en función de los cambios de comportamientos de la población y el aumento de la capacidad hospitalaria. Sus resultados ponen de relieve la utilidad del buen manejo de todos los aspectos implicados junto con la capacidad del hospital para lograr el control de epidemias. Sin embargo se proponen nuevos modelos de transmisión y control del VE en el África occidental utilizando patrones espaciotemporales de difusión en la región. Se requiere para ello la incorporación de la heterogeneidad espacial en el proceso de transmisión y datos como: los cambios temporales en los comportamientos de la población, redes de contacto a distintas escalas espaciales, patrones de movilidad de la población, la adhesión a las medidas de control de infecciones en los hospitales, y las tasas de hospitalización y de casos reportados ${ }^{12}$.

Son los trabajadores sanitarios los de mayor riesgo en la transmisión, de ahí que en los últimos meses se haya trabajado especialmente en fortalecer la formación e información para el cuidado de la salud de estos trabajadores y se haya enfatizado especialmente en la necesidad de un riguroso entrenamiento de este colectivo en la forma de ponerse y quitarse el equipo de protección personal, que siempre debe ser supervisado cuidadosamente por un monitor y se han elaborado guías que especifican la forma de uso de mascarilla N-95 o respirador purificador de aire forzado cuando se está prestando atención a un paciente con el Ébola ${ }^{13}$. La pregunta es: ¿Se está haciendo lo suficiente en la protección del trabajador sanitario? ${ }^{14}$. Sin duda uno de los caminos que en la práctica resultan más eficaces es el de trabajar ajustándose a estrictos protocolos ${ }^{15}$, que van mucho más allá de las clásicas precauciones universales, siempre necesarias, pero que resultan totalmente insuficientes en brotes como el actual ${ }^{16}$.

La epidemia de VE, a finales de diciembre de 2013, salió de África Occidental y dio lugar a un brote formidable en áreas como Guinea, Liberia, Sierra Leona y Nigeria. Esta enfermedad zoonótica tiene una alta tasa de mortalidad y su transmisión es de persona a persona a través de la sangre o fluidos corporales por exposición, lo que puede poner en peligro los trabajadores sanitarios de primera línea si hay una falta de control de la infección por no seguir estrictas normas o por falta de disponibilidad o errores de manejo en el uso del equipo de protección personal adecuado. Actualmente, no existe un tratamiento estándar para VE, por lo que la mejor terapia es la prevención, y se trata de identificar con prontitud a los pacientes y prevenir una mayor propagación, lo que requiere de los sanitarios tomar conciencia del riesgo en los viajes y conocer la historia de contacto para pacientes con síntomas constitucionales ${ }^{17}$.

En Estados Unidos las autoridades de salud pública instan a los trabajadores sanitarios que han de actuar en primera línea de la asistencia para que sean especialmente cuidadosos en la aplicación de los protocolos en aquellos pacientes que presentan síntomas de sospecha, que hayan viajado recientemente a África Occidental o estado en contacto con otras personas que pueden haber estado expuestos a EVD. La Organización Mundial de la Salud (OMS) indica que los trabajadores de la salud son particularmente vulnerables a la EVD, y que uno de los grandes momentos de riesgo para ellos es el previo al diagnóstico o durante el periodo de observación, cuando aún no se han colocado las precauciones de aislamiento. Es recomendación básica que en los hospitales se apliquen rigurosamente las políticas de control de las infecciones, con la necesidad de uso del equipo de protección adicional cuando hay fluidos corporales en el entorno del paciente ${ }^{18}$.

El riesgo es tanto para médicos, enfermeros, personal auxiliar y técnicos de laboratorio. En este último colectivo se requiere un estricto cumplimiento de los reglamentos y protocolos en patologías como ésta, transmitidas por la 
sangre y fluidos, mediante el uso de barreras apropiadas consistentes en guantes, bata, gafas, máscara para cubrir la nariz y la boca y pantalla de plexiglás, puesto que se pueden generar salpicaduras de materiales potencialmente infecciosos. Es por ello imperativo que todos los directores de laboratorio, trabajando con personal de control de infecciones y con la seguridad institucional, evalúen sus políticas hospitalarias sobre pacientes potencialmente infecciosos y proporcionen un ambiente seguro tanto para pacientes, como para trabajadores ${ }^{19}$.

Una revisión epidemiológica llevada a cabo por el equipo de virus ébola de la OMS durante 9 meses, en la que participaron 61 colaboradores en cinco países del oeste de África (Guinea, Liberia, Nigeria, Senegal y Sierra Leona), muestra datos epidemiológicos de interés: la mayoría de los pacientes tienen entre 15-44 años de edad y el 49,9\% son varones, estimándose que la tasa de letalidad es del $70,8 \%$ entre las personas con evolución clínica conocida de la infección. Según los datos observados se prevé que la afectación sea de 5.740 personas en Guinea, 9.890 en Liberia y 5.000 en Sierra Leona, superando los 20.000 en total.

Estos datos indican que, sin mejoras drásticas en las medidas de control, se espera que el número de casos y muertes por VE tiendan a seguir aumentando de cientos a miles por semana en los próximos meses ${ }^{20}$.

Vistas las cifras que se manejan y su alarmante crecimiento, en base a una estimación aproximativa del número de casos de epidemia de VE que pueden llegar a producirse en Liberia y Sierra Leona, el gobierno de Estados Unidos y las organizaciones internacionales recientemente anunciaron compromisos de apoyo mediante medidas que se implementen rápidamente y de forma sostenida ${ }^{21}$.

En lo que todos los autores se muestran de acuerdo es en la magnitud del problema y en la necesidad de actuaciones coordinadas y globalizadas ${ }^{22}$. El mundo científico ha ido incorporando publicaciones de forma gradual e incorporando aportaciones en lo que afecta a las características clínicas, epidemiológicas y de consecuencias para la salud pública de esta enfermedad. La Sociedad Americana de Medicina Tropical e Higiene (ASTMH) ha estado profundamente involucrada con el brote EVD y numerosos de sus miembros han jugado un papel importante en el tratamiento de la epidemia, incluidos los médicos y epidemiólogos que trabajan en la primera línea de la epidemia y con gran riesgo personal, las autoridades de salud pública que guían los esfuerzos de control en África y en otras partes, y los expertos de medicamentos y vacunas trabajan con el objetivo de acometer productos eficaces. La reunión anual de la ASTMH sirvió como foro de debates de expertos oportunos sobre EVD, pero también destacó los desafíos políticos de esta crisis en particular en concordancia con lo ya reseñado por otros autores ${ }^{23}$.

\section{DISCUSIÓN}

Aunque se trata de una infección conocida desde 1967, no es hasta diez años después cuando se encuentra la primera referencia en MEDLINE. Sin embargo, es a partir de 2010 cuando surgen de forma masiva publicaciones referentes a esta patología en concordancia con el incremento en el número de casos detectados tanto en países sudafricanos como, cada vez en mayor número, de casos importados a Europa.

$\mathrm{Al}$ menos el 50\% de las publicaciones en cualquiera de los términos de búsqueda corresponden a los últimos 5 años, destacando los relacionados con el concepto genérico de virus ébola, infección, tratamiento o patogénesis, siendo mucho más reducidas las revisiones en cualquiera de los conceptos de búsqueda.

La mayor parte de las publicaciones destacan el aumento creciente de personas afectadas, la virulencia de los casos y la necesidad de coordinación y colaboración institucional para actuar en su control, seguimiento y, especialmente en su prevención.

\section{CONCLUSIÓN}

Cabe destacar idea general presente en las publicaciones científicas de actuación conjunta, de potenciar los conocimientos, la detección precoz y, especialmente la prevención, con el apoyo requerido en todos los países de las Instituciones y de los Organismos implicados.

\section{REFERENCIAS BIBLIOGRÁFICAS}

1. Na W, Park N, Yeom M, Song D. Ebola outbreak in Western Africa 2014: what is going on with Ebola virus? Clin Exp Vaccine Res. 2015 Jan; 4(1):17-22. doi: 10.7774/ cevr.2015.4.1.17. Epub 2015 Jan 30.

2. Rodríguez Milord D. Enfermedades emergentes y reemergentes: amenaza permanente. Resumed. 2001; 14(2):37-40. Disponible en: http://www.bvs.sld.cu/ revistas/res/vol14_2_01/res01201.htm. [consultado el 15 de enero de 2015].

3. Wiwanitkit V. Ebola virus infection: what should be known? N Am J Med Sci 2014 Nov; 6 (11):549-52. doi: 10.4103/1947-2714.145458. 
4. Walter Ledermann D. Ébola: Corta y reciente historia de un joven virus. Rev Chil Infect Edición aniversario 2003: $113-14$.

5. Emond RT, Evans B, Bowen ET, Lloyd G.Ebola virus infectons Br Med J. 1977 Aug;2(6086): 539-44.

6. Emond RT, Evans B, Bowen ET, Lloyd G. A case of Ebola virus infection. Br Med J. 1977 Aug 27; 2(6086): 541-4.

7. Martin P, Laupland KB, Frost EH, Valiquette L. Laboratory diagnosis of Ebola virus disease. Intensive Care Med. 2015 May; 41(5): 895-8. doi: 10.1007/s00134015-3671-y. Epub 2015 Jan 31.

8. Zhejiang da xue. Epidemiology of Ebola virus disease. Zhejiang Da Xue Xue bao Yi Xue Bang 2014; Nov; 43(6): 621-45.

9. Chowell G, Nishiura H. Transmission dynamics and control of Ebola virus disease (EVD): a review.BMC Med 2014 Oct 10; 12(1): 196.

10. Miller LA, Stanger E, Senesi RG, DeLuca N, Dietz P, Hausman L, et al. Use of a Nationwide Call Center for Ebola Response and Monitoring During a 3-Day Houseto-House Campaign - Sierra Leone, September 2014. MMWR Morb Mortal Wkly Rep. 2015 Jan; 64(1): 28-9.

11. Drake JM, Kaul RB, Alexander LW, O’Regan SM, Kramer AM, Pulliam JT, Ferrari MJ, Park AW. Ebola cases and health system demand in Liberia. PLoS Biol. 2015 Jan 13; 13(1): e1002056.

12. Tambo E, Ugwu EC, Ngogang JY. Need of surveillance response systems to combat Ebola outbreaks and other emerging infectious diseases in African countries. Infect Dis Poverty. 2014 Aug 5; 3: 29.

13. Chowell G, Nishiura H. Characterizing the transmission dynamics and control of ebola virus disease. PLoS Biol 2015 Jan 21; 13 (1); 1-8.
14. With strengthened guidelines for health care workers, the $\mathrm{CDC}$ ups its game against the deadly Ebola virus. ED Manag. 2014 Dec; 26 (12): 133-6.

15. Johnson SR. Do Ebola precautions go far enough? Mod Healthc 2014 Aug 25; 44(34): 8.

16. Von Drehle D. The new Ebola protocols. Time 2014 Oct 27; 184(16): 20-3.

17. Gershon RR, Karkashian C, Felknor S. Universal precautions: an update. Heart Lung 1994 Jul-Aug; 23(4): 352-8.

18. Tseng CP, Chan YJ. Overview of Ebola virus disease in 2014. J Chin Med Assoc. 2015 Jan; 78(1): 51-5.

19. Public health experts urge U.S. hospitals to be prepared as Ebola outbreak accelerates. ED Mang. 2014 Oct; 26(10): 109-13.

20. Katz LM, Tobian AA. Ebola virus disease, transmission risk to laboratory personnel, and pretransfusion testing. Transfusion. 2014 Dec; 54(12): 3247-51. doi: 10.1111/ trf.12913.

21. WHO Ebola Response Team. Collaborators (61) Ebola virus disease in West Africa--the first 9 months of the epidemic and forward projections.N. England J Med. 2014 Oct; 371(16): 1481-95.

22. Meltzer MI, Atkins CY, Santibañez S, Knust B, Petersen BW, Ervin ED, et al. Estimating the future number of cases in the Ebola epidemic--Liberia and Sierra Leone, 2014-2015. MMWR Surveill Summ. 2014 Sep 26; 63(3): $1-14$.

23. Rosenthal PJ, Bausch DG. Perspectives on Ebola. Am J Trop Med Hyg. 2015 Feb 4; 92(2): 219-20. doi: 10.4269/ ajmh.14-0831.

Para citar este artículo: Vicente-Herrero M, López-González A, Ramírez-Iñiguez de la Torre M, Capdevila-García L, Terradillos-García M, Aguilar-Jiménez E. Infección por virus del Ébola. Corta historia, larga repercusión. Duazary. 2015 dic; 12 (2): 174 - 181 